\title{
LINC00037 Inhibits Proliferation of Renal Cell Carcinoma Cells in an Epidermal Growth Factor Receptor-Dependent Way
}

\author{
Xiaohui Gong ${ }^{\mathrm{a}} \quad$ Xianjin Du ${ }^{\mathrm{b}} \quad$ Yong Xuc $^{\mathrm{c}}$ Wenze Zheng ${ }^{\mathrm{d}}$ \\ ${ }^{a}$ Key Laboratory of Arrhythmia, Ministry of Education, East Hospital, Tongji University School of \\ Medicine, Shanghai; bepartment of Emergency, Renmin Hospital of Wuhan University, Wuchang, \\ Wuhan; 'Department of Nephrology, Huai'an Second People's Hospital, The Affiliated Huai'an Hospital \\ of Xuzhou Medical University, Huai'an; dDepartment of Anesthesiology, East Hospital, Tongji University \\ School of Medicine, Shanghai, China
}

\section{Key Words}

Linc00037 • LncRNA • Clear cell renal cell carcinoma • EGFR

\begin{abstract}
Background/Aims: LINC00037 has previously been reported to be up-regulated in clear cell renal cell carcinoma (ccRCC), however, the underlying mechanism remained unknown. In this study, we designed to investigate the functional role of LINC00037 in ccRCC. Methods: LINC00037 knockdown and re-expressing 786-O and A498 cells were established. CCK8 assay and EdU assay were performed to evaluate the proliferation rates of ccRCC cells. Flow cytometry assay was performed to detect the cell apoptosis and cell cycle. Subcutaneous injection xenotransplantation mouse model was used to observe the role of LINC00037 in tumor growth in vivo. Mass spectrometry (MS) was performed to find the interacting partner of LINC00037 and RNA immunoprecipitation (RIP) was carried out to validate their interaction. Results: We found that knockdown of LINC00037 resulted in inhibited cell proliferation with activated apoptosis and cell cycle arrest in vitro. Over-expression of LINC00037 in LINC00037 knockdown cells restored and enhanced cell proliferation. In vivo mouse model indicated reduced tumor progression by LINC00037 depletion and promoted tumor progression by LINC00037 overexpression. LINC00037 could bind to epidermal growth factor receptor (EGFR) and increase the protein level of EGFR. Conclusion: LINC00037 could inhibit proliferation of ccRCC in an epidermal growth factor receptor-dependent way.
\end{abstract}




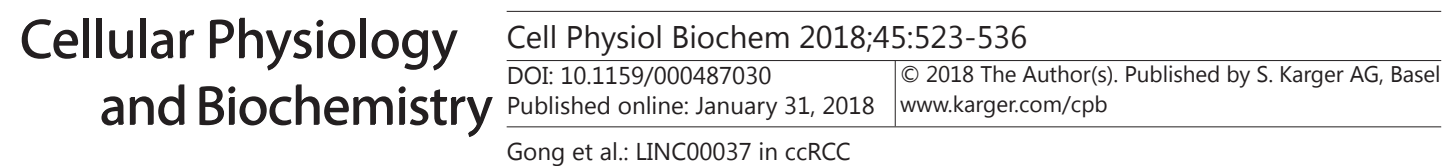

\section{Introduction}

Clear cell renal cell carcinoma (ccRCC) accounts for approximately $70 \%$ of renal cancer, which is one of the most common cancers, with approximately 202, 000 cases and 102, 000 deaths per year around the world [1, 2]. In clinical, RCC is characterized by anonymous symptoms and early metastasis $[3,4]$. Early detection and selection of accurate targets for ccRCC could be beneficial to improve of prognosis of ccRCC patients $[5,6]$.

Long noncoding RNAs (lncRNAs) are non protein coding RNAs ranging from $200 \mathrm{nt}$ to $100 \mathrm{~kb}$ in length [7]. The past decade has witnessed the discovery of diverse lncRNAs involved in physiological and pathological processes [8-12]. Many lncRNAs have been reported as important regulators in CCRCC, and several were also verified as biomarkers for early diagnosis and prognostic prediction for ccRCC $[13,14]$.

It is of vital significance to clarify the underlying mechanisms of molecular changes in ccRCC thus can contribute new strategies for the diagnosis and therapies to improve the prognosis. Whereas the functional roles and clinical value of the great mass of lncRNAs in the occurrence and progression of ccRCC remain largely unknown.

Sequencing technologies and bioinformatics analyses are widely used to analyze the expression patterns of IncRNAs in diverse diseases and to identify potential disease associated genes [15-17]. Here we studied a IncRNA, LINC00037, which was high expressed in ccRCC tissues comparing to corresponding normal tissues [18-20]. We further explored its functional role in RCC cells and the underlying mechanism, which demonstrated that LINC00037 may be a therapeutic target for ccRCC.

\section{Materials and Methods}

\section{Cell lines and animals}

The ccRCC cell lines A498 and 786-0 cells were conventionally maintained in Dulbecco's improved Eagle's medium (DMEM) (Invitrogen, Grand Island, NY, USA) supplemented with $10 \%$ fetal bovine serum (FBS) (Gibco, Carlsbad, CA, USA), L-glutamine (2 mM), penicillin (100 U/ml), and streptomycin (100 mg/ $\mathrm{ml}$ ). The cells were grown in an environment of $37^{\circ} \mathrm{C}, 5 \%$ CO2. We purchased ccRCC cell lines A498 and 786-0 cells from the Shanghai Institute of Biochemistry and Cell Biology (Chinese Academy of Sciences, Shanghai, China).

4-8 weeks old male BALB/c nu/nu mice from the Experimental Animal Center of Yangzhou University were fostered in the absence of pathogen conditions. All the animals were subjected to humanitarian care, and all experiments were performed in accordance with the Guide for the Care and Use of Laboratory Animals.

\section{Cell transfection}

As mentioned above, Lentivirus plasmids constructed with the short hairpin RNA (shRNA) of the LINC00037 sequence (lentiviral-short hairpin RNA, Lv-shRNA) were used to transfect A498 and 786-0 cells. The lentiviral plasmids were constructed using the interference sequence (named Lv-NC) as a control. The lentiviral vector (pll3.7) was inserted with the synthetic and purified LINC00037 gene fragment, termed LvLINC00037. The packaged recombinant lentivirus then transfected LINC00037 knockdown cells. The shRNA of EGFR was used for the targeting sequence: GGCTGGTTATGTCCTCATT. Construction of lentivirus plasmids using shRNA of EGFR (EGFR-shRNA), was designed for transforming ccRCC cells as mentioned above.

\section{Quantitative real-time PCR}

For total RNAs extraction from fresh liver tissues and cells, TRIzol reagent (Invitrogen) was used. The SurePrep Nuclear or Cytoplasmic RNA Purification Kit (Life Science SOURCE, Biovision, Milpitas, CA, USA) was used to extract RNA from the cytoplasm and nuclear. Reverse transcriptase (TaKaRa) kit was used for reverse transcription of total RNA (500ng) in order to detect mRNA. Has-5S was used for internal control. SYBR Green Mastermix kit (TaKaRa, Tokyo, Japan) was used to detect LINC00037 and mRNA expression level by quantitative real-time PCR and triplicate assays were used for analysis on the ABI Prism 7900HT 


\section{Cellular Physiology Cell Physiol Biochem 2018;45:523-536 \begin{tabular}{ll|l} 
and Biochemistry Published online: January 31, 2018 & $\begin{array}{l}\text { @ } 2018 \text { The Author(s). Published by S. Karger AG, Basel } \\
\text { www.karger.com/cpb }\end{array}$ \\
\hline
\end{tabular}}

Gong et al.: LINC00037 in cCRCC

(Applied Biosystems, Foster City, CA, USA) according to the instructions. Primer 3.0 software was used for designing primer sequences (http://www.simgene.com/Primer3). Primer sequences were as follows:: Has5S: Forward: 5'-GGAGAGGGAGCCTGAGAAACG-3' and Reverse: 5'-TTACAGGGCCTCGAAAGAGTCC-3', human LINC00037: Forward: 5'-CACGAGTGTAGTGCCCAGTT-3' and Reverse: 5'-GGTCAGGGACCTTTGTCGTT-3' and human EGFR: Forward: 5' - TCCTCTGGAGGCTGAGAAAA-3' and Reverse: 5' -GGGCTCTGGAGGAAAAGAAA-3'.

\section{Western blotting}

Total proteins were extracted from cultured cells using radio-immunoprecipitation assay buffer added with protease and phosphatase inhibitors (Beyotime, Nantong, China) and then were quantified by the Bradford assay (Bio-Rad Laboratories, Hercules, CA, USA). Each lane was added with the same amount of protein samples $(30 \mu \mathrm{g})$. Sodium dodecyl sulfate polyacrylamide gel electrophoresis (SDS-PAGE) was used for protein separation and then the separated protein was transferred to a polyvinylidene fluoride membrane. Antibodies against EGFR (Cell Signaling Technology, Danvers, MA, USA) and glyceraldehydephosphate dehydrogenase (GAPDH) (Cell Signaling Technology) were used for immunoblotting. The integrated density of the bands was quantified by ImageJ software (NIH, Bethesda, MD, USA).

\section{Flow cytometry analysis (FCA)}

For apoptosis detection, the Annexin V-FITC/PI Apoptosis Detection Kit (Vazyme Biotech, China) was used and cells were treated with $0.05 \mathrm{mM} \mathrm{H}_{2} \mathrm{O}_{2}$ for 2 hours to stimulate apoptosis. For cell cycle measurement, a Cell cycle Assay Kit (Vazyme Biotech) was used. Finally, the FACS Calibur flow cytometer served as cell analysis with CellQuest software (BD Biosciences, New York, NY, USA).

\section{Cell proliferation and invasion assay}

Cell proliferation was assessed with a CCK8 kit (Vazyme Biotech, China) and a Cell-Light EdU Apollo567 In vitro Kit (RiboBio, Guangzhou, China). For CCK8 detection, transfected cells $\left(2 \times 10^{3}\right)$ were transferred to 96-well plates, incubated for 24, 48, 72 and 96 hours, then added with CCK8 reagent and finally incubated at $37^{\circ} \mathrm{C}$ for 2 hours. For absorption measurement, microplate reader at $450 \mathrm{~nm}$ (ELX-800; Bio-Tek, Winooski, VT, USA) was used. For 5-ethynyl-2'-deoxyuridine (EdU) detection, the transfected cells $\left(2 \times 10^{5}\right)$ were first transferred to Glass Botttom Cell Culture Dishes (Nest Biotechnology, NJ, USA) and then treated as described. Finally, the treated cells were measured by laser confocal scanning microscopy. For invasion assay, the Transwell units (Corning Costar, Tewksbury, MA, USA) percolated with Matrigel (BD Biosciences, New York, NY, USA) were used to evaluate. Cells $\left(2 \times 10^{4}\right.$ cells/well $)$ were transferred to the upper chamber in DMEM without FBS and the lower chamber was full of DMEM containing 10\% FBS as a chemokine. After 48 hours of incubation at room temperature, the filters were gathered and fixed with $4 \%$ paraformaldehyde and then dyed with $0.1 \%$ crystal violet. Remove the non-invasive tumor cells from the top of the filters with a cotton swab and then count the cells through the filter under an optical microscope.

\section{Subcutaneous xenotransplantation model}

Cells $\left(5 \times 10^{6}\right)$ knocked down or overexpressed LINC00037 in ccRCC and were inoculated into the bilateral armpits of each BALB/C nude mice in a subcutaneous manner. After five weeks of inoculation, the mice were all killed and tumors were weighed. Tumor tissues were stripped as a whole.

\section{Agarose gel electrophoresis}

The agarose powder $(0.5 \mathrm{~g})$ was dissolved in the $0.5 \%$ Tris-acetate-EDTA (TAE) buffer of $50 \mathrm{ml}$ and heated to near boiling state followed by $2.5 \mu \mathrm{L}$ of GoldView (Beyotime, China, Nantong, China) and then mixed. The cDNA was made by reverse transcription of the total RNA extracted from the cell lines, and the cDNA was mixed with the loading buffer (Beyotime, Nantong, China) and the mixture was added to the wells. $0.5 \%$ TAE was used as the running buffer and electrophoresis was performed at $80 \mathrm{~V}$ for 40 minutes. Image Lab software with an ultraviolet (UV) transilluminator was performed to analyze data.

Mass spectrometry (MS)

Polyacrylamide gel was made according to the standard protocol. Twenty microliters of each sample were mixed with 10x running buffer (CapitalBio Corp., Beijing, China) and the mixture was added. The gel was operated at $120 \mathrm{~V}$ for 2.5 hours and then dyed by Fast Silver Stain Kit (Beyotime). Finally, the 


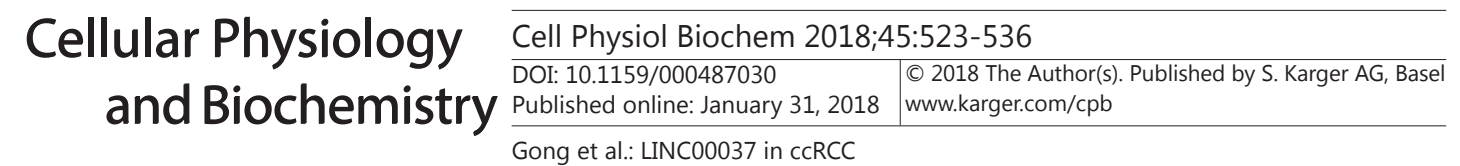

lanes were cut into ten pieces and placed in Eppendorf tubes respectively. $\mathrm{NH}_{4} \mathrm{HCO}_{3}(50 \mathrm{mM})$ was loaded and using a pipette broke the gel into pieces. The gel solution was then digested overnight at $37^{\circ} \mathrm{C}$ using trypsin (Promega, Fitchburg, WI, USA). Tubes were shaken, added methyl cyanide (HPLC grade) and then centrifuged at room temperature for 2 minutes. After centrifugation, the supernatant was sucked into a clean tube and dried at $60^{\circ} \mathrm{C}$ by means of a vacuum concentrator. The peptides were analyzed by LC-MS/MS of nano-LC together with Orbitrap Q Exactive mass spectrometer (Thermo Scientific, Waltham, MA, USA) at a scan range of $\mathrm{m} / \mathrm{z} 400-1500$. The original files were analyzed using the Thermo Proteome Discoverer (1.4.0.288) software (http://www.thermoscientific.com/en/product/proteome-discoverer-software.html) platform. MS/MS spectra of protein identified were retrieved from the protein database (human-refseq20140303-71465s.fasta, National Center of Biotechnology Information).

RNA immunoprecipitation (RIP)

RIP was conducted with a Magna RIP RNA-Binding Protein Immunoprecipitation Kit (Millipore, Bedford, MA, USA). The co-precipitated RNAs were determined by quantitative real-time PCR after pulling down assay with anti-EGFR antibody (Cell Signaling Technology).

\section{Statistical analysis}

The results of quantitative real-time PCR were showed in the way of mean \pm S.E.M. The statistical differences between clinical and demographic characteristics were checked by Student's $t$ test and $\chi^{2}$ test. Statistical analysis was conducted by STATA version 9.2 (Stata Corp., College Station, TX, USA) and SPSS version 18.0 (SPSS Inc, Chicago, IL, USA) and presented with the GraphPad prism software (GraphPad Software, San Diego, CA, USA). Finally, $\mathrm{P}<0.05$ was recognized statistically significant in all cases.

\section{Results}

LINC00037 was highly expressed in ccRCC

LINC00037 is located on chromosome $22(22 \mathrm{q} 11.21)$ and it is not a conserve gene as indicated by the homologous analysis (Fig. 1A). Also, it is also reported as a non protein coding RNA in the LNCipedia database and in HUGO Gene Nomenclature Committee (HGNC) database (Fig. 1B). LINC00037 is widely found in various tissues of homo sapiens (Fig. 1B). So we searched the several databases and found studies on LINC00037 in ccRCC consistently presented that LINCO0037 was highly expressed in ccRCC compared with that of heathy controls [18-20] (Fig. 1C-G); however no studies investigated its function and the underlying mechanism in ccRCC.

\section{LINC00037 promoted proliferation but not invasion of ccRCC cells in vitro}

To detect the functional role of LINC00037 in regulatingthe biological behaviors of cells, shRNAs plasmids packaged into lentivirus plasmid, termed Lv-shRNA were used to knockdown LINC00037 in 786-O and A498 cells (Fig. 2A and 2B). The cell proliferation rate assay was performed with a CCK8 kit and an EdU kit, which showed that LINC00037 knockdown resulted in significantly inhibited proliferative ability of 786-0 and A498 cells. When the expression of LINC00037 was rescued by LINC00037 overexpression with lentivirus plasmids containing LINC00037 cDNA sequence (Lv-LINC00037) in 786-0 and A498 cells, the reduced cell proliferation rate was restored and improved (Fig. 2C-G). The role of LINC00037 in regulating cell invasion was also explored, however, no significant difference was observed in Transwell assay (data not shown).

\section{LINC00037 inhibited apoptosis of ccRCC cells and alleviated cell cycle arrest}

We further potential role of LINCO0037 in regulating ccRCC cell apoptosis and cell cycle with flow cytometry assay. It showed that when LINC00037 was knockdown, ccRCC cells presented higher level of apoptosis, and this effect was reversed by re-expression of LINC00037 in ccRCC cells (Fig. 3A). The cell cycle assay showed that LINC00037 knockdown resulted in significant cell cycle arrest. Over-expression of LINC00037 in LINC00037 knockdown cells have re-established the cell ability with reduced cell cycle arrest (Fig. 3B). 


\section{Cellular Physiology Cell Physiol Biochem 2018;45:523-536 \begin{tabular}{l|l} 
and Biochemistry Published online: January 31, 2018 & $\begin{array}{l}\text { ○ 2018 The Author(s). Published by S. Karger AG, Basel } \\
\text { www.karger.com/cpb }\end{array}$ \\
\hline
\end{tabular}

Fig. 1. LINC00037 was aberrantly up-regulated in ccRCC.(A) LINC00037 is located on chromosome $22(22 q 11.21)$ and it is not a conserve gene as indicated by the homologous analysis (http://genome.ucsc.edu/cgi-bin/ hgTracks?db=hg38\&last VirtModeType $=$ default $\&$ lastVirtModeExtraState $=\&$ virtModeType $=$ defau lt\&virtMode $=0$ \&nonVirt Position $=\&$ position $=\mathrm{chr}$ 22\%3A18970514-18994628\&hgsid=606067865_ Kfo49eyeQdVI32GZ9aGGlFYegaeB). (B) Upper panel: LINC00037 is also reported as a non protein coding RNA in the LNCipedia database and in HUGO Gene Nomenclature Committee (HGNC) database. Lower panel: LINC00037 is widely found in various tissues of homo sapiens (http:// biogps.org/\# goto= genereport\&id=26220). (C-D) Increased level of LINC00037 in hereditary and non-hereditary ccRCC tissues was detected in comparison with renal cortex and normal renal tissues (Analysis on Oncomine database with data from study of Beroukhim et al. [18]. (E-F) Increased level of LINC00037 was detected in ccRCC tissues compared with the normal renal tissues (Analysis on Oncomine database with data from study of Gumz et al. [19] (E) and Lenburg et al. [20] (F)). (G) Level of LINC01225 was detected in ccRCC tissues compared with the normal renal tissues. The relative expression of LINC00037 was log transformed and presented as box plots. (Analysis on lncRNAtor database with data from TCGA database). Box plot explanation: upper horizontal line of box, 75th percentile; lower horizontal line of box, 25th percentile; horizontal bar within box, median; upper horizontal bar outside box, 95th percentile; lower horizontal bar outside box, 5 th percentile. Data were presented as mean \pm S.E.M.

\section{LINC00037 acted as a promoter of tumor growth in vivo}

To study the effect of LINCO0037 on tumor growth in vivo, BABL/c nude mice were used to construct the xenotransplantation model through subcutaneously injection with Lv-NC, Lv-shRNA or Lv-LINC00037 transfected ccRCC cells. It showed that ccRCC cells after LINC00037 depletion presented significantly attenuated tumor growth, which can be restored and improved by LINC00037 re-expression (Fig. 4A and 4B). 

Cellular Physiology Cell Physiol Biochem 2018;45:523-536 \begin{tabular}{l|l|l} 
and B: 10.1159/000487030 & (c) 2018 The Author(s). Published by S. Karger AG, Basel
\end{tabular} and Biochemistry Published online: January 31, 2018 www.karger.com/cpb

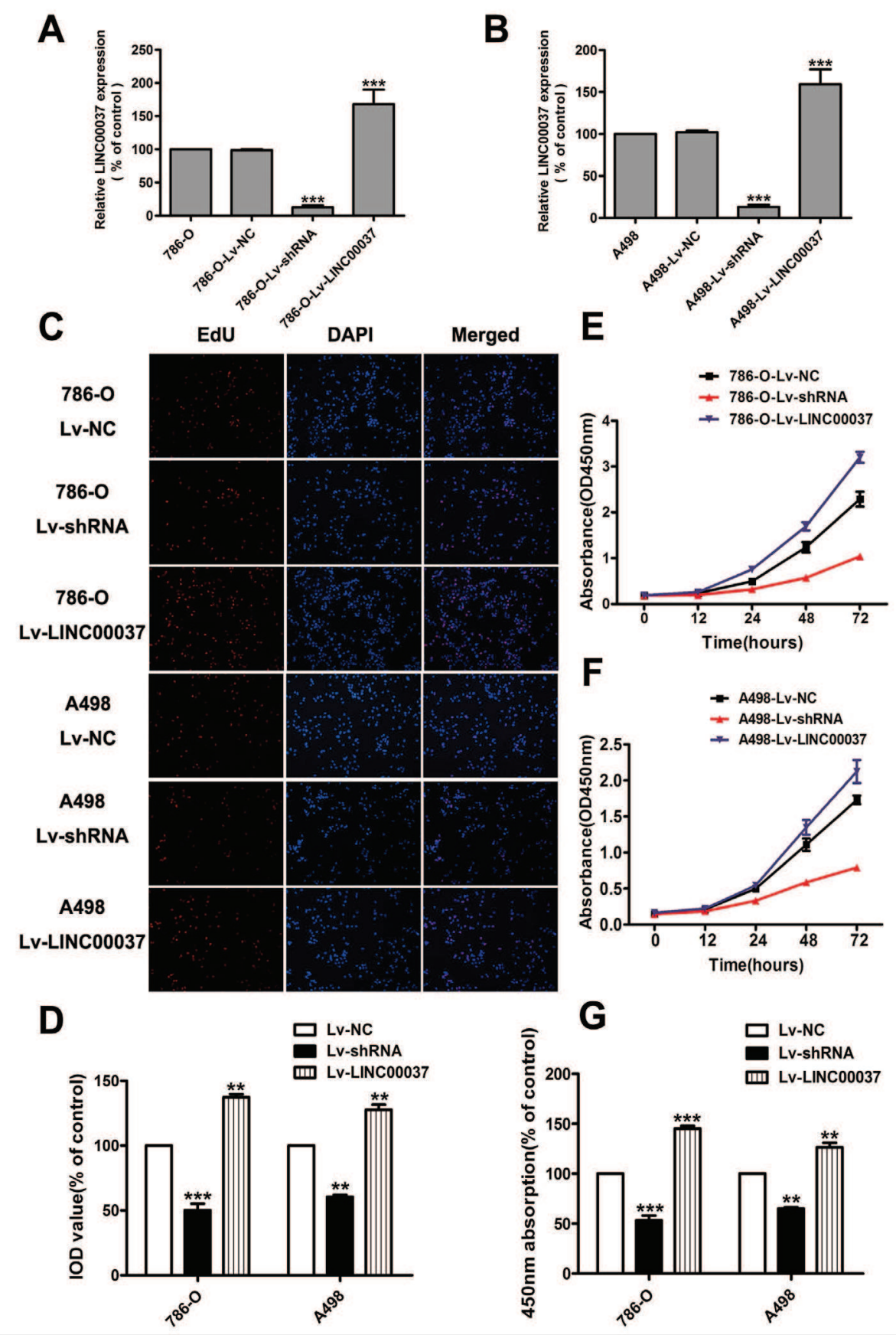

Fig. 2. LINC00037 promoted cell proliferation in vitro. (A) Real-time PCR assay detected LINC00037 in 786-0 cells. (B) Real-time PCR assay detected LINC00037 in A498 cells. (C) Edu assay demonstrated the functional role of LINC00037 in cell proliferation. (200x) (D) The results of Edu assay at $24 \mathrm{~h}$. Knockdown LINC00037 reduced the proliferation of ccRCC, compared with the control cells; up-regulation of LINC00037 in LINC00037 depletion cells improved cell proliferation. The integral optical density (IOD) values of cells transfected with control plasmids were normalized to 100\%. (E-F) CCK8 assay indicated that down-regulation of LINC01225 inhibited growth of 786-0 and A498 cells; cell growth was prompted in LINC00037 depletion cells after LINC00037 overexpression. (G) Absorbance at $450 \mathrm{~nm}$ was collected and calculated as the mean \pm SEM. Data were collected and provided at $24 \mathrm{~h}$ after cultivation, and data of cells treated with control plasmids was normalized to $100 \%$. All experiments were performed independently for triple times. $\left({ }^{* *} \mathrm{P}<0.01, * * * \mathrm{P}<0.01\right)$. 

Cellular Physiology Cell Physiol Biochem 2018;45:523-536

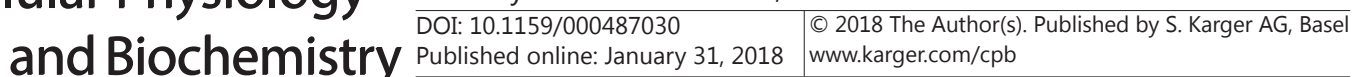 Gong et al.: LINC00037 in ccRCC

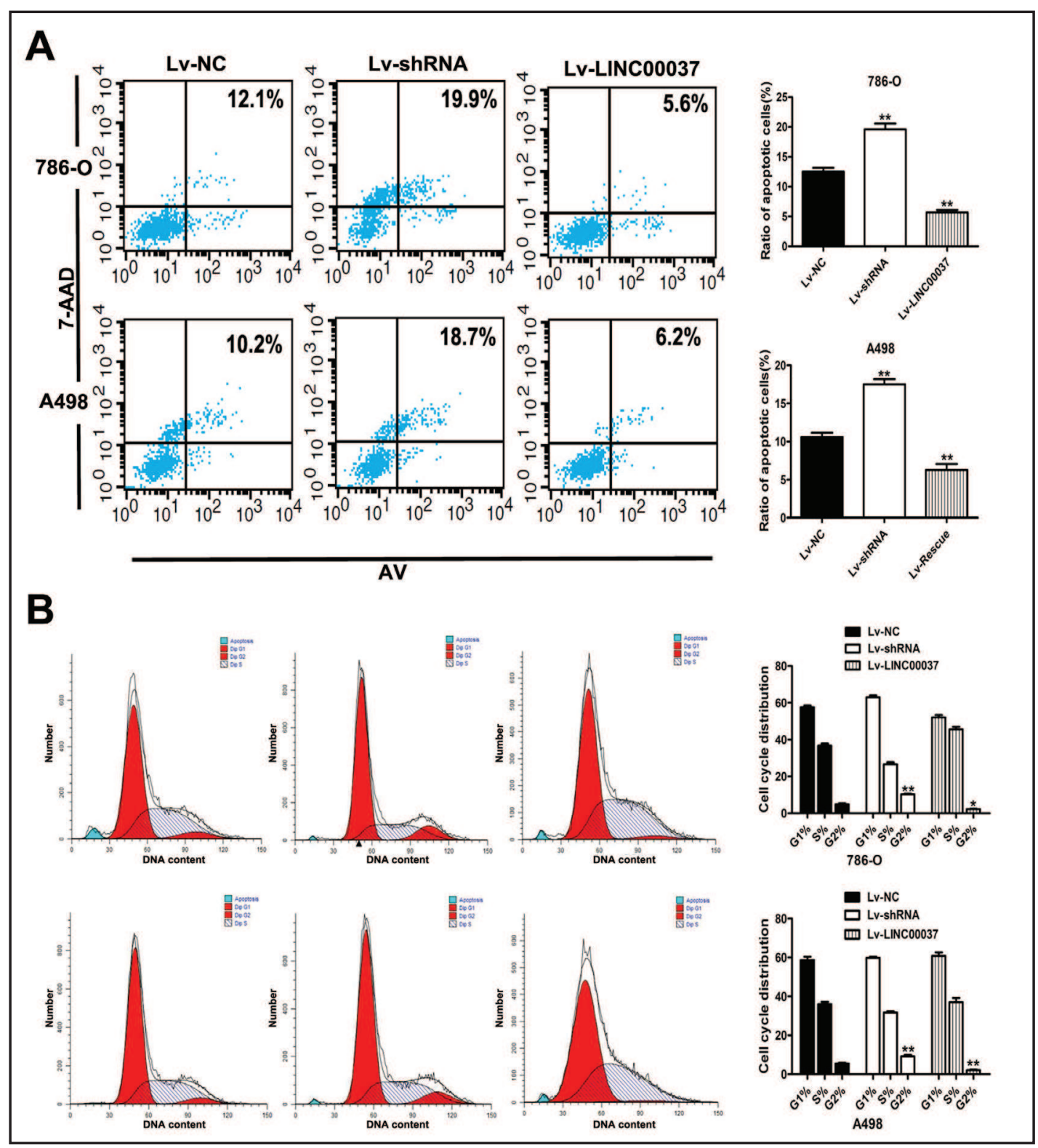

Fig. 3. Knockdown of LINC00037 increased cell apoptosis and cell cycle arrest. (A) Left panels: After challenging for $48 \mathrm{~h}$ with Lv-NC, Lv-shRNA or Lv-LINC00037 plasmids, cell apoptosis analysis were performed on flow cytometry. Right panels: Cells apoptosis rates were calculated and presented in the column chart. (B) Left panels: After treatment with Lv-NC, Lv-shRNA or Lv-LINC00037 plasmids, cell cycle analysis were performed on flow cytometry. Right panels: The ratios of G1, S, or G2 phase were calculated and presented in the column chart. All experiments were carried out independently for three times and showed as the mean \pm SEM $\left({ }^{*} \mathrm{P}<0.05,{ }^{* *} \mathrm{P}<0.01,{ }^{* * *} \mathrm{P}<0.001\right)$.

\section{LINC00037 promoted HCC growth through interacting with EGFR}

In order to determine the underlying role of LINC00037 in ccRCC, we firstly detected the subcellular location of LINC00037 transcript by real-time PCR after amplifying with separating nuclear and cytoplasm RNA in 786-0 cells. The result showed that LINC00037 was located primarily in the cytoplasm of 786-0 cells (Fig. 5A). This indicated that LINC00037 may function via interacting with components in the cytoplasm, based on which, we conducted the RNA pull-down assay with the biotin-labeled lncRNA. Through rapid silver staining, we 


\section{Cellular Physiology \\ Cell Physiol Biochem 2018;45:523-536 \\ \begin{tabular}{l|l}
\hline DOI: $10.1159 / 000487030$ & (c) 2018 The Author(s). Published by S. Karger AG, Base
\end{tabular} and Biochemistry Published online: January 31, 2018 www.karger.com/cpb \\ Gong et al.: LINC00037 in cCRCC}

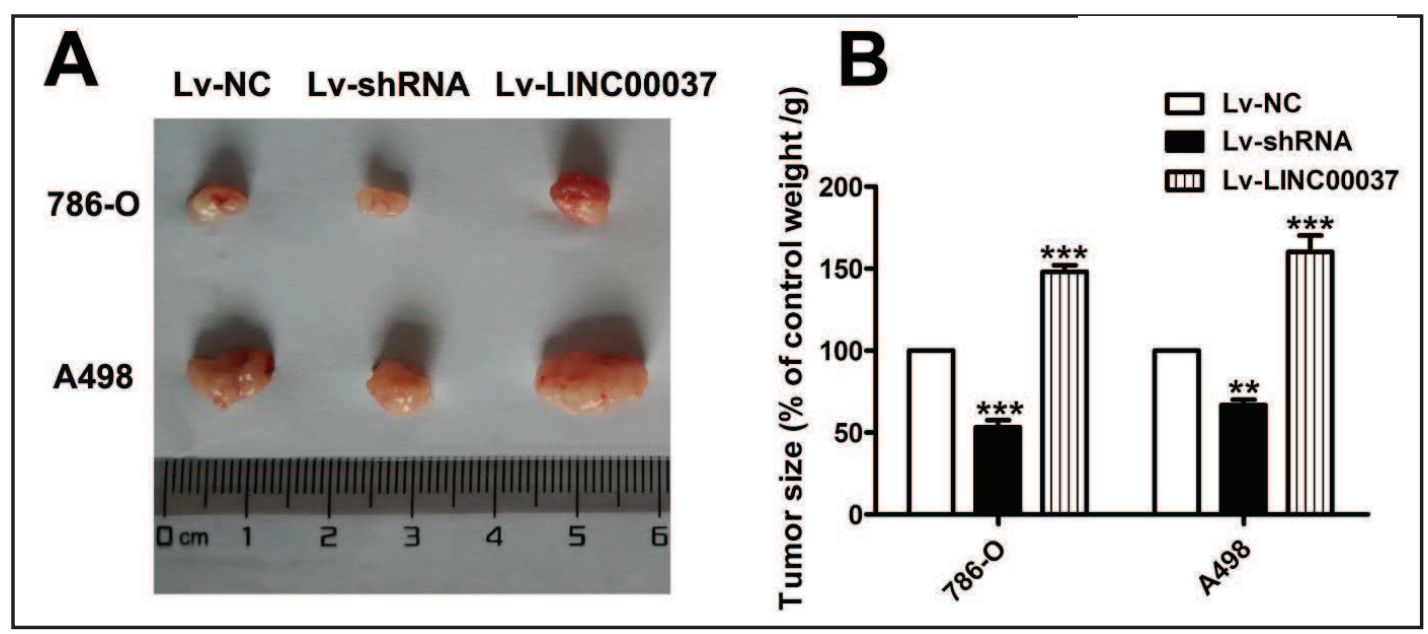

Fig. 4. LINC00037 depletion inhibited tumor growth in vivo.(A-B) The tumors constructed with SMCC7721 or MHCC97H cells subcutaneously transplanting into the right groin of BALB/C nude mice were stripping out (A) and the weigh was measured (B) $(n=8)$. Data of cells treated with control plasmids was normalized to $100 \%$. All experiments were carried out independently for three times. Data are presented as the mean \pm SEM $\left({ }^{* *} \mathrm{P}<0.01,{ }^{* * *} \mathrm{P}<0.001\right)$.

found that protein band at the $\sim 170 \mathrm{kDa}$ location indicated most significant difference in amount (Fig. 5B). Then protein bands at the $\sim 170 \mathrm{kDa}$ were cut for mass spectrum screening, and we found that peptide of EGFR was most differently enriched between two groups (Fig. 5C).

Then we detected the expression of EGFR by both quantitative real-time PCR and western blotting in ccRCC cells with LINC00037 depletion or overexpression. We found that there was significant difference at the protein level (Fig. 5D and 5E), however, no significant change was found in mRNA level of EGFR (data not shown). Therefore, we hypothesized that LINC00037 may function through interacting with EGFR protein in ccRCC.

Then we used anti-EGFR antibody to performed the protein pull-down assay. The pulldown products were collected for RNA extraction. Through real-time PCR and agarose gel electrophoresis, we found that LINC00037 was enriched in anti-EGFR pull-down products (Fig. 6A-E), which suggested that LINC00037 could directly bind to EGFR protein in ccRCC.

\section{Discussion}

Studies on the expression patterns and regulatory mechanisms of functional lncRNAs in ccRCC may provide promising therapeutic targets and novel diagnostic or prognostic biomarkers for ccRCC. In this study, we discussed the functional role of LINC00037 in ccRCC. We further explored its functional roles and the underlying mechanism in RCC cells, which demonstrated that LINCO0037 is a potential therapeutic target for ccRCC.

As described in the NCBI database, LINC00037, also called DiGeorge syndrome critical region gene 5 (DGCR5), is a human noncoding RNA validated by the Human Gene Nomenclature Committee. It is located at chromosome 22q11.21 with 2113 bp and has six exons. Previous study by Huang et al. [21], reported that LINC00037 was low expressed in serum of patients with HCC, and may act as a potential biomarker for the diagnosis and prognosis in HCC. Liu et al. [22] performed a study with data from The Cancer Genome Atlas - Cancer Genome (TCGA) database, which suggested that LINC00037 was low expressed in and correlated with better OS in lung squamous cell carcinoma. And Yong et al. [23] found that that the down-regulation of LINCO0037 predicted poor prognosis in pancreatic ductal adenocarcinoma (PDAC). These implied the tumor suppressive role of LINC00037. However, 


\section{Cellular Physiology Cell Physiol Biochem 2018;45:523-536

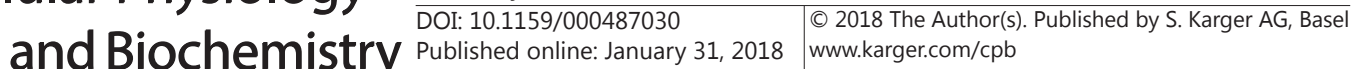 Gong et al.: LINC00037 in ccRCC}

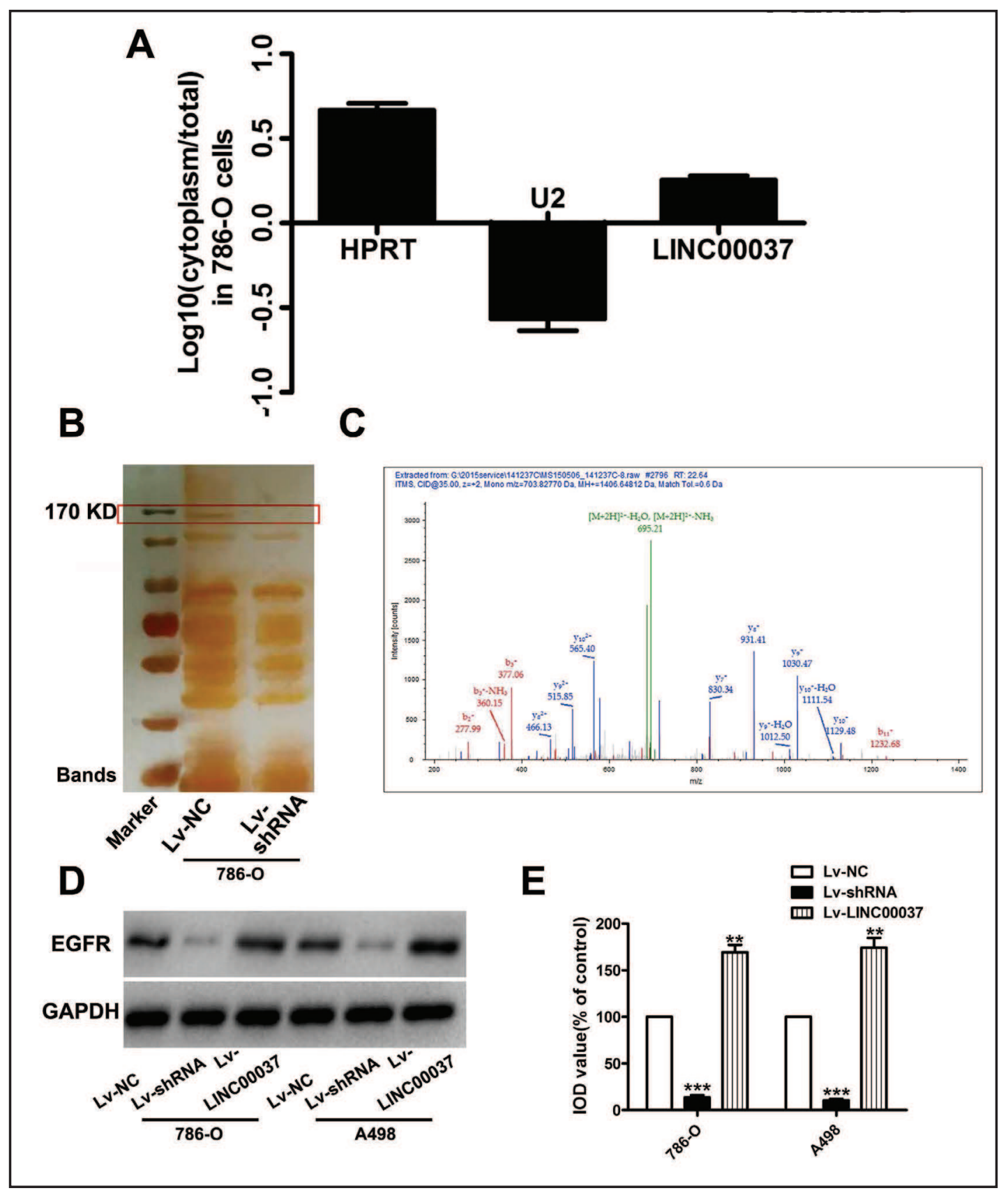

Fig. 5. MS assay indicated LINC00037 could bind to and regulate EGFR expression. (A) Real-time PCR assay detected the subcellular location of LINC00037 in 786-0 cells. (B) Polyacrylamide gel stained with rapid silver staining showed that EGFR was reduced in LINC00037 knocked down 786-0 cells. (C) MS analysis was performed to discover abnormally expressed protein due to LINC00037 depletion. As an example, trypsin digestion fragment (NYVVTDHGScVR) detected by MS was presented in the panel. $\mathrm{b}$ and y stands for $\mathrm{N}$-terminal and C-terminal collision-induced dissociation fragment ions. (D) EGFR protein expression level was detected by western blotting. Cells were treated with Lv-NC, Lv-shRNA and Lv-LINC00037 plasmids. (E) IOD value was calculated and showed. Data of cells treated with control plasmids was normalized to $100 \%$. All experiments were carried out independently for three times and showed as the mean $\pm \mathrm{SEM}\left({ }^{* *} \mathrm{P}<0.01\right.$, *** $\mathrm{P}<0.001$ ).

in ccRCC, several studies have reported that LINC00037 was highly expressed in ccRCC tissues compared to normal renal tissues, which consistently indicated the oncogenic role of 


\section{Cellular Physiology Cell Physiol Biochem 2018;45:523-536 and Biochemistry POI: 10.1159/000487030 2018 () 2018 The Author(s). Published by S. Karger AG, Basel \\ Gong et al.: LINC00037 in ccRCC}

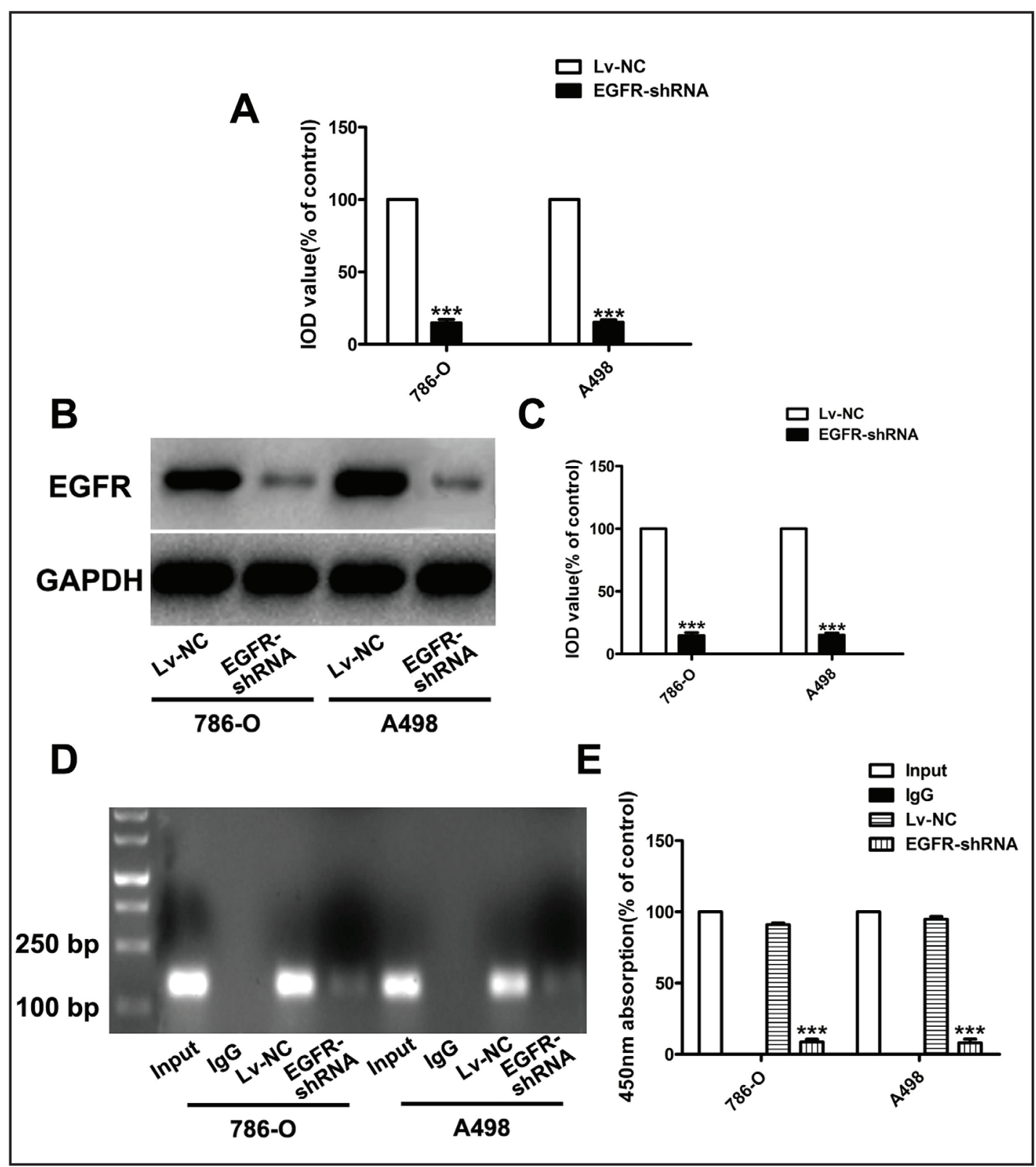

Fig. 6. RIP assay demonstrated the direct binding of LINC00037 and EGFR. (A-C) 786-0 cells and A498 cells were treated with shRNA constructed with Lentivirus packaging plasmid, termed EGFR-shRNA. The effect of EGFR-shRNA on the expression of EGFR in the level of mRNA and protein was detected. The IOD value of the western blotting bands was evaluated. (D) RIP was performed using an antibody against EGFR on extracts from 786-O cells and A498 cells with IgG as a negative control and MHCC97H cells treated with EGFR-shRNA as an additional control. (E) Enrichment of LINC00037 was normalized to the input as $100 \%$. IOD value was calculated and showed. All experiments were performed in triplicate and presented as the mean \pm S.E.M. $\left({ }^{* * *} \mathrm{P}<0.001\right)$.

LINC00037 in ccRCC[18-20]. In consideration of the contrasting roles predicted by studies of LINC00037 expression patterns, the underlying mechanism of LINC00037 in cancer should be investigated and clarified.

To study the function of LINC00037 in ccRCC, we firstly knockdown LINC00037 in two ccRCC cell lines, 786-0 and A498 cells. then we also re-expressed LINC00037 in the former LINC00037 knockdown ccRCC cells. In vitro study showed that absence of LINC00037 


\begin{tabular}{|c|c|c|}
\hline & Bioinformatic analysis & LINC 00037 was up-regulated in ccRCC \\
\hline \multirow{4}{*}{ 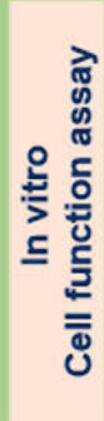 } & 786-O A498 & ccRCC celllines \\
\hline & $\begin{array}{cc}\text { LINC } 00037 & \text { LINC00037 } \\
\text { knockdown } & \text { re-overexpression }\end{array}$ & $\begin{array}{l}\text { koncdown and re-overexpressing } \\
\text { cCRCC celllines }\end{array}$ \\
\hline & Cell proliferation (CCK8 and EdU) & LINC00037 inhibited cell apoptosis \\
\hline & $\begin{array}{l}\text { Cell apoptosis and cell cycle } \\
\text { (Flowcytometry) }\end{array}$ & LINC 00037 alleviated cell cycle arrest \\
\hline 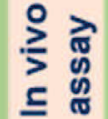 & $\begin{array}{c}\text { Subcutaneous } \\
\text { xenotransplantation mouse } \\
\text { model }\end{array}$ & LINC00037 promoted tumor growth \\
\hline \multirow{3}{*}{ 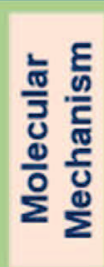 } & Subcellular location & LINC00037 located in cytoplasm \\
\hline & $\begin{array}{l}\text { Mass Spectrometry } \\
\text { and Western Blot Assay }\end{array}$ & $\begin{array}{l}\text { LINC } 00037 \text { knockdown reduced } \\
\text { EGFR in protein level }\end{array}$ \\
\hline & $\begin{array}{l}\text { Construction of } \\
\text { EGFR knockdown } \\
\text { ccRCC cells }\end{array}$ & EGFR protein could bind to LINC 00037 \\
\hline
\end{tabular}

Fig. 7. The details of the study design and main results were presented in the flowchart.

resulted in attenuated cell proliferation, however, the invasive ability of ccRCC cells was not significantly changed. Re-expression of LINCO0O37 effectively restored and enhanced the proliferative ability but not affect the invasive ability of ccRCC cells. Moreover, cell apoptosis and cell cycle arrest was obviously prompted by LINC00037 depletion, and the former effects can be reversed by LINC00037 re-expression. From the in vivo study, we observed that knockdown LINC00037 in ccRCC cells significantly inhibited the tumor growth and reexpressing LINC00037 observably reversed the growth inhibition. The mechanism of IncRNA is closely associated with its location. LncRNAs in cell nucleus often act as a transcription factor, whereas those in cytoplasm usually function through binding to certain proteins. To explore the subcellular location of LINC00037 in ccRCC cells, real-time PCR analysis with separated nuclear and cytoplasm RNA was performed. The result showed that LINC00037 was located primarily in the cytoplasm of 786-0 cells, therefore may function through directly binding to certain proteins. Subsequently, we carried out the RNA pull-down assay and MS assay in 786-0 cells with LINC00037 depletion or not, which showed that EGFR was most differently enriched between two groups.

EGFR is vitally involved in regulating cell survival and proliferation [24, 25]. And in model systems of autocrine stimulation of EGFR, or EGFR overexpression and mutation, consequent transformation has been observed [26,27]. EGFR may function through activating a network of signaling pathways, involving Ras, phosphoinositide 3-kinase and the signal transducer, activator of transcription family [28-30], and so forth in ccRCC [31,32].

Previous studies have found that lncRNAs may increase the level of certain proteins by directly binding to and stabilizing the later [33-35]. However, whether lncRNAs modify ccRCC development and progression via EGFR dependent pathway remains unknown. Several lncRNAs have been reported to bind to EGFR protein, such as LINC00125[28] and LINC-EGFR[36]. In our study, we observed that the protein level but not the mRNA level of EGFR was significantly reduced as a result of LINC00037 knockdown in ccRCC cells, which 


\section{Cellular Physiology Cell Physiol Biochem 2018;45:523-536 \begin{tabular}{l|l|l} 
and Biochemistry & Published online: January 31, 2018 & $\begin{array}{l}\text { () 2018 The Author(s). Published by S. Karger AG, Basel } \\
\text { www.karger.com/cpb }\end{array}$ \\
\hline
\end{tabular} \\ Gong et al.: LINC00037 in ccRCC}

can be reversed by LINC00037 overexpression. These suggested that LINC00037 may affect EGFR signaling primarily via regulating EGFR protein. To investigate whether the regulation is directly, we performed EGFR protein pull-down assay with anti-EGFR antibody. It showed that LINC00037 was significantly enriched in the pull-down products as a compound with EGFR protein.

\section{Conclusion}

Our study showed the aberrantly up-regulation of LINC00037 in ccRCC, and further demonstrated that LINCO0037 played a crucial role in ccRCC through binding to and increasing the level of EGFR protein as a consequence. This may provide a promising therapeutic target for ccRCC. However, more studies are warranted for further investigation of the function of LINC00037 in the future.

\section{Disclosure Statement}

Authors involved have contributed adequately to this work and have no conflicts of interest to disclose

\section{Acknowledgements}

None.

The details of the study design and main results were presented in the flowchart (Fig. 7).

\section{References}

1 Capitanio U, Montorsi F: Renal cancer. Lancet 2016;387:894-906.

-2 Ljungberg B, Bensalah K, Canfield S, Dabestani S, Hofmann F, Hora M, Kuczyk MA, Lam T, Marconi L, Merseburger AS, Mulders P, Powles T, Staehler M, Volpe A, Bex A: Eau guidelines on renal cell carcinoma: 2014 update. Eur Urol 2015;67:913-924.

-3 Dabestani S, Marconi L, Hofmann F, Stewart F, Lam TB, Canfield SE, Staehler M, Powles T, Ljungberg B, Bex A: Local treatments for metastases of renal cell carcinoma: A systematic review. Lancet Oncol 2014;15:e549-561.

-4 Hakimi AA, Reznik E, Lee CH, Creighton CJ, Brannon AR, Luna A, Aksoy BA, Liu EM, Shen R, Lee W, Chen Y, Stirdivant SM, Russo P, Chen YB, Tickoo SK, Reuter VE, Cheng EH, Sander C, Hsieh JJ: An integrated metabolic atlas of clear cell renal cell carcinoma. Cancer Cell 2016;29:104-116.

5 Brown C: Targeted therapy: An elusive cancer target. Nature 2016;537:S106-108.

6 Jayson GC, Kerbel R, Ellis LM, Harris AL: Antiangiogenic therapy in oncology: Current status and future directions. Lancet 2016;388:518-529.

7 Beermann J, Piccoli MT, Viereck J, Thum T: Non-coding rnas in development and disease: Background, mechanisms, and therapeutic approaches. Physiol Rev 2016;96:1297-1325.

8 Hu HB, Jie HY, Zheng XX: Three circulating lncrna predict early progress of esophageal squamous cell carcinoma. Cell Physiol Biochem 2016;40:117-125.

-9 Luo G, Wang M, Wu X, Tao D, Xiao X, Wang L, Min F, Zeng F, Jiang G: Long non-coding rna meg3 inhibits cell proliferation and induces apoptosis in prostate cancer. Cell Physiol Biochem 2015;37:2209-2220.

10 Pan Y, Li C, Chen J, Zhang K, Chu X, Wang R, Chen L: The emerging roles of long noncoding rna ror (lincrnaror) and its possible mechanisms in human cancers. Cell Physiol Biochem 2016;40:219-229.

11 Qiu ZL, Shen CT, Sun ZK, Wei WJ, Zhang XY, Song HJ, Luo QY: Circulating long non-coding rnas act as biomarkers for predicting 131i uptake and mortality in papillary thyroid cancer patients with lung metastases. Cell Physiol Biochem 2016;40:1377-1390. 


\section{Cellular Physiology Cell Physiol Biochem 2018;45:523-536 \begin{tabular}{ll|l}
\hline DOI: 10.1159/000487030 & (c) 2018 The Author(s). Published by S. Karger AG, Basel
\end{tabular} and Biochemistry Published online: January 31, 2018 www.karger.com/cpb}

Gong et al.: LINC00037 in cCRCC

12 Wang L, Chen Z, An L, Wang Y, Zhang Z, Guo Y, Liu C: Analysis of long non-coding rna expression profiles in non-small cell lung cancer. Cell Physiol Biochem 2016;38:2389-2400.

-13 Malouf GG, Zhang J, Yuan Y, Comperat E, Roupret M, Cussenot O, Chen Y, Thompson EJ, Tannir NM, Weinstein JN, Valero V, Khayat D, Spano JP, Su X: Characterization of long non-coding rna transcriptome in clear-cell renal cell carcinoma by next-generation deep sequencing. Mol Oncol 2015;9:32-43.

14 Wu Y, Wang YQ Weng WW, Zhang QY, Yang XQ Gan HL, Yang YS, Zhang PP, Sun MH, Xu MD, Wang CF: A serum-circulating long noncoding rna signature can discriminate between patients with clear cell renal cell carcinoma and healthy controls. Oncogenesis 2016;5:e192.

15 Iyer MK, Niknafs YS, Malik R, Singhal U, Sahu A, Hosono Y, Barrette TR, Prensner JR, Evans JR, Zhao S, Poliakov A, Cao X, Dhanasekaran SM, Wu YM, Robinson DR, Beer DG, Feng FY, Iyer HK, Chinnaiyan AM: The landscape of long noncoding rnas in the human transcriptome. Nat Genet 2015;47:199-208.

-16 Rizvi AH, Camara PG, Kandror EK, Roberts TJ, Schieren I, Maniatis T, Rabadan R: Single-cell topological rnaseq analysis reveals insights into cellular differentiation and development. Nat Biotechnol 2017;35:551560 .

17 Zhu S, Li W, Liu J, Chen CH, Liao Q, Xu P, Xu H, Xiao T, Cao Z, Peng J, Yuan P, Brown M, Liu XS, Wei W: Genome-scale deletion screening of human long non-coding rnas using a paired-guide rna crispr-cas 9 library. Nat Biotechnol 2016;34:1279-1286.

18 Beroukhim R, Brunet JP, Di Napoli A, Mertz KD, Seeley A, Pires MM, Linhart D, Worrell RA, Moch H, Rubin MA, Sellers WR, Meyerson M, Linehan WM, Kaelin WG, Jr., Signoretti S: Patterns of gene expression and copy-number alterations in von-hippel lindau disease-associated and sporadic clear cell carcinoma of the kidney. Cancer Res 2009;69:4674-4681.

19 Gumz ML, Zou H, Kreinest PA, Childs AC, Belmonte LS, LeGrand SN, Wu KJ, Luxon BA, Sinha M, Parker AS, Sun LZ, Ahlquist DA, Wood CG, Copland JA: Secreted frizzled-related protein 1 loss contributes to tumor phenotype of clear cell renal cell carcinoma. Clin Cancer Res 2007;13:4740-4749.

20 Lenburg ME, Liou LS, Gerry NP, Frampton GM, Cohen HT, Christman MF: Previously unidentified changes in renal cell carcinoma gene expression identified by parametric analysis of microarray data. BMC Cancer 2003;3:31.

-21 Huang R, Wang X, Zhang W, Zhangyuan G, Jin K, Yu W, Xie Y, Xu X, Wang H, Sun B: Down-regulation of Incrna dgcr5 correlates with poor prognosis in hepatocellular carcinoma. Cell Physiol Biochem 2016;40:707-715.

-22 Liu B, Chen Y, Yang J: Lncrnas are altered in lung squamous cell carcinoma and lung adenocarcinoma. Oncotarget 2017;8:24275-24291.

-23 Yong S, Yabin Y, Bing Z, Chuanrong Z, Dianhua G, Jianhuai Z, Weidong Y, Shuming W, Ling L: Reciprocal regulation of dgcr5 and mir-320a affects the cellular malignant phenotype and 5-fu response in pancreatic ductal adenocarcinoma. Oncotarget 2017

-24 Lanaya H, Natarajan A, Komposch K, Li L, Amberg N, Chen L, Wculek SK, Hammer M, Zenz R, PeckRadosavljevic M, Sieghart W, Trauner M, Wang H, Sibilia M: Egfr has a tumour-promoting role in liver macrophages during hepatocellular carcinoma formation. Nat Cell Biol 2014;16:972-981, 971-977.

-25 Lu F, Chen Y, Zhao C, Wang H, He D, Xu L, Wang J, He X, Deng Y, Lu EE, Liu X, Verma R, Bu H, Drissi R, Fouladi M, Stemmer-Rachamimov AO, Burns D, Xin M, Rubin JB, Bahassi el M, Canoll P, Holland EC, Lu QR: Olig2dependent reciprocal shift in pdgf and egf receptor signaling regulates tumor phenotype and mitotic growth in malignant glioma. Cancer Cell 2016;29:669-683.

26 Chong CR, Janne PA: The quest to overcome resistance to egfr-targeted therapies in cancer. Nat Med 2013;19:1389-1400.

-27 Petak I, Schwab R, Orfi L, Kopper L, Keri G: Integrating molecular diagnostics into anticancer drug discovery. Nat Rev Drug Discov 2010;9:523-535.

-28 Klinger B, Sieber A, Fritsche-Guenther R, Witzel F, Berry L, Schumacher D, Yan Y, Durek P, Merchant M, Schafer R, Sers C, Bluthgen N: Network quantification of egfr signaling unveils potential for targeted combination therapy. Mol Syst Biol 2013;9:673.

29 Navas C, Hernandez-Porras I, Schuhmacher AJ, Sibilia M, Guerra C, Barbacid M: Egf receptor signaling is essential for k-ras oncogene-driven pancreatic ductal adenocarcinoma. Cancer Cell 2012;22:318-330.

-30 Xiang J, Bandura J, Zhang P, Jin Y, Reuter H, Edgar BA: Egfr-dependent tor-independent endocycles support drosophila gut epithelial regeneration. Nat Commun 2017;8:15125. 

Cellular Physiology Cell Physiol Biochem 2018;45:523-536
\begin{tabular}{ll|l} 
DOI: 10.1159/000487030 & (c) 2018 The Author(s). Published by S. Karger AG, Basel
\end{tabular} and Biochemistry Published online: January 31, 2018 www.karger.com/cpb

Gong et al.: LINC00037 in cCRCC

-31 Cossu-Rocca P, Muroni MR, Sanges F, Sotgiu G, Asunis A, Tanca L, Onnis D, Pira G, Manca A, Dore S, Uras MG, Ena S, De Miglio MR: Egfr kinase-dependent and kinase-independent roles in clear cell renal cell carcinoma. Am J Cancer Res 2016;6:71-83.

32 Dordevic G, Matusan Ilijas K, Hadzisejdic I, Maricic A, Grahovac B, Jonjic N: Egfr protein overexpression correlates with chromosome 7 polysomy and poor prognostic parameters in clear cell renal cell carcinoma. J Biomed Sci 2012;19:40.

-33 Wang X, Zhang W, Tang J, Huang R, Li J, Xu D, Xie Y, Jiang R, Deng L, Zhang X, Chai Y, Qin X, Sun B: Linc01225 promotes occurrence and metastasis of hepatocellular carcinoma in an epidermal growth factor receptordependent pathway. Cell Death Dis 2016;7:e2130.

34 Yan C, Chen J, Chen N: Long noncoding rna malat1 promotes hepatic steatosis and insulin resistance by increasing nuclear srebp-1c protein stability. Sci Rep 2016;6:22640.

- 35 Lin A, Hu Q, Li C, Xing Z, Ma G, Wang C, Li J, Ye Y, Yao J, Liang K, Wang S, Park PK, Marks JR, Zhou Y, Zhou J, Hung MC, Liang H, Hu Z, Shen H, Hawke DH, Han L, Zhou Y, Lin C, Yang L: The link-a lncrna interacts with ptdins (3, 4,5)p3 to hyperactivate akt and confer resistance to akt inhibitors. Nat Cell Biol 2017;19:238-251.

36 Jiang R, Tang J, Chen Y, Deng L, Ji J, Xie Y, Wang K, Jia W, Chu WM, Sun B: The long noncoding rna lnc-egfr stimulates t-regulatory cells differentiation thus promoting hepatocellular carcinoma immune evasion. Nat Commun 2017;8:15129. 